\title{
A simple approach to symmetrical and unsymmetrical ureas
}

\author{
G. M. Viana'; J. A. Ferrão' J. D. Senra²; M. G. Vasconcelos ${ }^{2}$; A. B. C. Simas ${ }^{2}$ and L. \\ C. S. Aguiar ${ }^{1^{*}}$ \\ ${ }^{1}$ Instituto de Química (Lab 617-Bloco A; UFRJ; Cidade Universitária), ${ }^{2}$ NPPN/UFRJ \\ *luciasequeira@yahoo.com.br.
}

Keywords: urea; thiourea; potassium dichloroiodate

\section{INTRODUCTION}

Mild and efficient methods for the synthesis of substituted ureas have continued to attract a widespread interest for a long time due to their diverse biological activity. Here we wish to report a new facile methodology to prepare substituted ureas, just treating their respective thioureas with aqueous potassium dichloroiodate $\left(\mathrm{KICl}_{2}\right) .{ }^{1} \mathrm{An}$ interesting oxidation reaction in organic chemistry is the oxidation of thioureas. Depending on the oxidizing agent, reaction conditions and the substitution pattern of thioureas, a variety of products have been isolated. ${ }^{2}$ Different from the literature reports dealing with methodologies describing that thioureas can be transformed into ureas (lead tetraacetate ${ }^{2}$; oxone ${ }^{3}$; manganese dioxide ${ }^{4}$; tetrabutylammonium perio-date ${ }^{5}$ ), our approach also allows the simultaneous synthesis of iodinated aryl-ureas.

\section{RESULTS AND DISCUSSION}

Several alkyl and aryl thioureas 1-2 were prepared by the reaction of their corresponding amines and benzyl or phenyl isothiocyanate. Their reactions with aqueous solution of $\mathrm{KICl}_{2}$ were investigated at room temperature and reflux. We observed that both aryl and alkyl thioureas led to their respective ureas, in high yield, when the reaction was maintained at r.t., for 30 minutes (Scheme 1).

Scheme 1. Oxidation of thioureas with $\mathrm{KICl}_{2}(\mathrm{aq})$

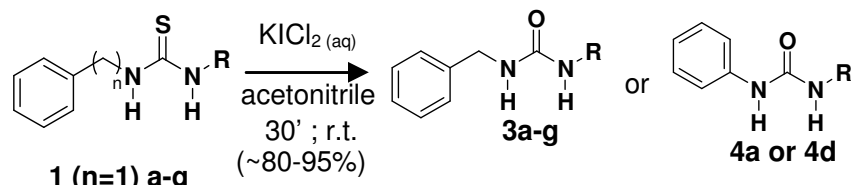

$2(n=0) a, d$

$\mathbf{R}=\mathbf{a}: \mathrm{iPr} ; \mathbf{b}: \mathrm{Bn} ; \mathbf{c}: \mathrm{Bu}$; $: \mathrm{Ph}$ e: $\mathrm{Ph}-\mathrm{o-Me}$ f: $\mathrm{Ph}-p-\mathrm{NO}_{2} ; \mathbf{g}: \mathrm{Ph}-p-\mathrm{OMe}$

However, when thioureas $\mathbf{2 a}$ and $\mathbf{1 d}$ were treated with $\mathrm{KICl}_{2}$, under reflux conditions for 1.5 hour, the respective iodinated ureas $5(69 \%)$ and $6(91 \%)$ were directly obtained $\left({ }^{1} \mathrm{H},{ }^{13} \mathrm{C}\right.$ NMR; Figure 1).
Refluxing 2a for a longer period (7h) led to the same monoiodinated urea $\mathbf{5}$. Other aryl thioureas (1e-g) had already been submitted to reflux for 1.5 hour. While thioureas 1e $(\mathrm{R}=\mathrm{Ph}-o-\mathrm{Me})$ and $1 \mathrm{~g}(\mathrm{R}=\mathrm{Ph}-p$ $\mathrm{OMe}$ ) led to different products than $3 \mathrm{e}$ and $\mathbf{3 g}$ (structures under investigation), the $p-\mathrm{NO}_{2}$-phenylsubstituted thiourea $\mathbf{1 f}$ led to the same urea $\mathbf{3 f}$.
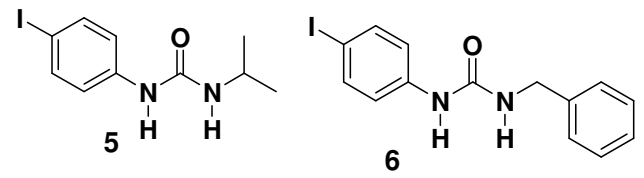

Figure 1. lodinated aryl ureas

Our research group has also been interested in the development of mild and general protocols for palladium-catalyzed cross-coupling reactions. We then pursued the combination of both methodologies in the design of (novel) biaryl ureas by SuzukiMiyaura reaction in aqueous medium. At first, we reacted $p$-iodo- $N$-phenyl- $N$ '-isopropylurea $\mathbf{5}$ with phenylboronic acid in the presence of our $\mathrm{PdNPs}^{6}$ as catalyst. After some experimentation, we found that a pre-activation step of the urea (with catalyst) was a requisite for higher selectivity. The scope of this transformation to include other $p$-iodo- $N$-phenyl- $N R$ ureas ( $R=$ benzyl, phenyl) along with different phenylboronic acids is currently under investigation in our laboratory.

\section{CONCLUSION}

We reported on an efficient method for the synthesis of ureas (iodinated or not), from the reaction of their corresponding thioureas with aqueous solution of $\mathrm{KICl}_{2}$.

\section{CNPq / FAPERJ / CAPES / IQ-UFRJ}

\section{REFERENCES}

${ }^{1}$ Garden, S. J. et al, Tetrahedron Letters, 2001, 42, 2089.

${ }^{2}$ Debroy, A, et al, Bull. Chem. Soc. Jpn., 1984, 57, 315.

${ }_{3}^{3}$ Mohammadpoor-Baltork, I. et al, Synthetic Communications, 2003, 953.

${ }^{4}$ Sharma, T. C. et al, Bull. Chem. Soc. Jpn., 1978, 51, 1245.

${ }^{5}$ Pourali, A. R. et al, Monatshefte fuer Chemie, 2005, 136, 733

${ }^{6}$ Senra, J. D.; Malta, L. F. B.; Michel, R. C.; da Costa, M. E. H. M.; Aguiar,

L. C. S.; Simas, A. B. C.; Antunes, O. A. C. Adv. Synth. Catal., 2009, 351, 2411.

$14^{\text {th }}$ Brazilian Meeting on Organic Synthesis $-14^{\text {th }}$ BMOS - September 01-05, 2011-Brasilia, Brazil 